\title{
PHYTOCHEMISTRY, TOXICITY AND IN VITRO ANTITRYPANOSOMAL EFFICACY OF CRUDE AQUEOUS EXTRACT OF GUIERA SENEGALENSIS STEM BARK
}

\author{
A. A. Biu ${ }^{1}$, L. B. Buratai ${ }^{2}$, P. N. Onyedim ${ }^{2}$, I. U. Hambali ${ }^{3}$, S. I. Ngulde ${ }^{4} *$, M. Zakariah ${ }^{5}$ and \\ J. R. Lawal ${ }^{6}$ \\ ${ }^{1}$ Department of Veterinary Microbiology and Parasitology, Faculty of Veterinary Medicine, ${ }^{2}$ Department of \\ Biochemistry, Faculty of Science, ${ }^{3}$ Department of Veterinary Public Health and Preventive Medicine, \\ ${ }^{4}$ Department of Veterinary Physiology, Pharmacology and Biochemistry, ${ }^{5}$ Department of Veterinary Anatomy, \\ ${ }^{6}$ Department of Veterinary Medicine, Faculty of Veterinary Medicine, University of Maiduguri, Nigeria
}

\begin{abstract}
The crude aqueous extract of Guiera senegalensis stem bark was evaluated for its phytochemistry, acute toxicity and in vitro antitrypanosomal efficacy in this study. Tests for alkaloids, flavonoids, tannins, phlabotannins, saponins, steroids, cardenolides, terpenoids, cardiac glycosides, and anthraquinones were conducted. A total of 15 albino rats of both sexes were used and grouped into 5 (A to E) of 3 rats each. Groups A-D were intraperitoneally treated with graded doses of 100, 200, 400, $800 \mathrm{mg} / \mathrm{kg}$ body weight of the crude aqueous extract of G. senegalensis stem bark. Group E was treated with Physiological Saline Solution serving as the control. All groups were observed for 24 hours for clinical signs and death to determine the median lethal dose $\left(\mathrm{LD}_{50}\right)$. An in vitro experiment was carried out with 2 drops of blood from a donor rat added to $5 \mathrm{ml}$ of phosphate buffer glucose solution out of which $0.2 \mathrm{ml}$ was finally used at 40,20,10, 5, 2.5, 0.625, $0.313,0.156$ and 0.078 concentrations of the extract. The phytochemical screening for bioactive substances had tannins, terpenoids, alkaloids, flavonoids, saponins, anthraquinones and cardiac glycosides. Phlabotannins and cardenolides were not detected. The clinical signs observed were sluggishness, awkward posture, loss of appetite, starry hair coat and terminal death within 24 hours with $\mathrm{LD}_{50}$ value of $600 \mathrm{mg} / \mathrm{kg}$. The in vitro antitrypanosomal efficacy of the extract showed $100 \%$ inhibition of motility against Trypanosoma brucei at $20 \mathrm{mg} / \mathrm{ml}$. In conclusion, the crude aqueous extract of G. senegalensis stem bark contains phytochemical components that exhibit inhibitory trypanosomal activity.
\end{abstract}

Keywords: Guiera senegalensis stem bark, phytochemical components, acute toxicity, in vitro efficacy, Trypanosoma brucei

\section{INTRODUCTION}

Trypanosoma brucei, a parasitic haemoflagellate, is a blood protozoan that causes African trypanosomiasis (or sleeping sickness) in humans and Nagana in animals. There are 3 sub-species of T. brucei vis: T.b. brucei, T. $b$. gambiense and T. b. rhodesiense. It is endemic in some regions of sub-Saharan Africa, covering areas in about 37 countries containing more than 60 million people. An estimated 50,000 to 70,000 people are currently infected, however, reported cases are now below 10,000 in 2009 (WHO, 2011; 2012). The disease has spread beyond its original distribution in sub-Saharan Africa and is now present in South America, North Africa and large parts of Asia (Vanhollebeke et al., 2006). The existing treatments of trypanosomiasis have lots of challenges (Gutteridge, 1985). Therefore, there is a need to investigate a cheaper, more effective, easily available and less toxic chemotherapeutic agents for combating trypanosomiasis. Herbal preparations for the treatment of the disease still holds a strong potential in that some ethnomedicinal plants have been demonstrated to contain potent trypanocides (Igweh and Onabanjo, 1989; Nok, 1993; Atawodi, 2005).

Guiera senegalensis is a traditional medicinal plant used to treat various illnesses (Fiot et al., 2004). The branches, leaves, bark and roots of G. senegalensis are recommended for the treatment of stomach pain and dysenteric, syphilis, beriberi, leprosy and impotence diarrhea (Kerharo et al., 1948; Aniagu et al., 2005). The present study was therefore designed to determine the phytochemistry, acute toxicity and in vitro antitrypanosomal efficacy of $G$. senegalensis stem bark crude aqueous extract.

*Corresponding e-mail address: singulde@gmail.com 


\section{A. A. Biu and others}

\section{MATERIALS AND METHODS \\ Plant collection and identification}

The bark of G. senegalensis was collected within the University of Maiduguri Campus, Nigeria. The plant was authenticated by a botanist in the Department of Biological Science, Faculty of Science, University of Maiduguri, Nigeria.

\section{Plant processing and extraction}

Guiera senegalensis stem bark was thoroughly rinsed in tap water and shade dried in the Laboratory for 7 days at room temperature $\left(25^{\circ} \mathrm{C}\right)$, ground into powder and stored in a rubber container. One thousand grams of the stem bark powder was dissolved in four liters of distilled water and then shaken every six hours for 48 hours. The solution was filtered with a muslin cloth and then refiltered using Whatman's number 1 paper and was evaporated to dryness on a water bath at $40^{\circ} \mathrm{C}$.

\section{Phytochemical analysis}

Tests for alkaloids, flavonoids, tannins, phlabotannins, saponins, steroids, cardenolides, terpenoids, cardiac glycosides and anthraquinones were carried out as described by Trease and Evans (2002).

\section{Trypanosome stock}

Trypanosoma brucei was obtained from Nigeria Institute of Trypanosomiasis Research (NITR), Vom, Plateau State, Nigeria. The Trypanosome was passaged in donor rats before infection of the experimental rats, intraperitoneally with $0.1 \mathrm{ml}$ of saline diluted blood containing $1.5 \times 10^{6}$ trypanosomes. The level of parasitaemia was determined using the rapid matching method of Herbert and Lumsden (1976).

\section{Experimental animals}

Fifteen albino rats of both sexes weighing between 80 and $120 \mathrm{~g}$ obtained from University of Maiduguri were used for the study. The rats were kept in a well-ventilated Laboratory and maintained on a commercial poultry feed (Vital ${ }^{\circledR}$ Feeds Jos, Nigeria) and drinking water ad libitum.

\section{Acute toxicity study}

Fifteen albino rats were grouped into 5 (A to E) of 3 rats each weighed in grams and marked for easy identification. Groups A-D were intraperitoneally treated with graded doses of $100,200,400,800 \mathrm{mg} / \mathrm{kg}$ body weight with a concentration of $100 \mathrm{mg} / \mathrm{ml}$ of the extract based on method of Karber as modified by Aliu and Nwude (1982). Group E was treated with physiological saline solution serving as the control. The rats were observed for 24 hours for clinical signs and death. The $\mathrm{LD}_{50}$ of G. senegalensis stem bark was then calculated using the modified arithmetic method of Karber (Aliu and Nwude, 1982).

\section{In vitro experiment}

The experiment was carried out with 2 drops of blood from a donor rat added to $5 \mathrm{ml}$ of phosphate buffer glucose solution out of which $0.2 \mathrm{ml}$ was finally used. A serial dilution of this stock solution was done using phosphate buffer glucose to obtain descending concentrations of 40,20, 10, 5, 2.5, 0.625, 0.313, 0.156 and 0.078 into different test tubes. Evaluation of the in vitro trypanosomal inhibition was performed in a test tube with 2 drops of T. brucei infected blood inoculated into each test tube containing the various concentrations of the extract and incubated at $37^{\circ} \mathrm{C}$. Parasite count was then monitored on a glass counting chamber covered with a cover slip and observed under the light microscope at x40 magnification. The number of motile parasites was counted under the light microscope using improved Neubauer's chamber at $30 \mathrm{mins}, 1 \mathrm{hr}, 1 \mathrm{hr} 30 \mathrm{mins}$ and $2 \mathrm{hrs}$ post inoculation. The percentage inhibition of motility was calculated using this formula:

(Parasite count of control - Parasite count of treated / Parasite count of control) x 100

\section{Statistical analysis}

Inhibition of motility counts were expressed as mean \pm standard deviation (SD), ranges and percentages. 
The crude aqueous extract of Guiera senegalensis

\section{RESULTS AND DISCUSSION}

The phytochemistry indicating the bioactive substances present in G. senegalensis stem bark is shown in Table 1. The phytochemical screening for bioactive substances had indicated the presence of tannins, terpenoids, alkaloids, flavonoids, saponins, anthraquinones and cardiac glycosides. Phlabotannins and cardenolides were not detected.

Table 1. Phytochemical components of Guiera senegalensis stem bark crude aqueous

\begin{tabular}{llll}
\hline Component & Test & Observation & Scoring \\
\hline Alkaloids & Dragendorff's & Brownish-red colour & + \\
Tannins & Ferric chloride & Deep red colour & + \\
Flavonoids & Pew's & Red colour & + \\
Anthraquinones & Borntrigger's & Violet colour & + \\
Terpenoids & Lierberman-Buchard & Violet colour & + \\
Saponins & Frothing & Persistence foam & + \\
Cardenolides & Keller - Killani & None & - \\
Phlabotannins & Hydrogen chloride & None & - \\
Carbohydrates & Molisch's & Red colour & + \\
Glycosides & Salkowski's & Reddish brown colour & + \\
\hline
\end{tabular}

Key: $+=$ detected, $-=$ not detected

The dose of the extract that produced $100 \%$ mortality was $800 \mathrm{mg} / \mathrm{kg}$ body weight. The calculated $\mathrm{LD}_{50}$ was $600 \mathrm{mg} / \mathrm{kg}$ body weight (Table 2). At doses of 100,200 and $200 \mathrm{mg} / \mathrm{kg}$ body weight, there was no mortality. The clinical signs observed following the intraperitoneal administration of the extract to the albino rats were sluggishness, awkward posture, loss of appetite, starry hair coat and terminal death within 24 hours.

Table 2. Median lethal dose $\left(\mathrm{LD}_{5 \mathrm{o}}\right)$ of crude aqueous extract of Guiera senegalensis stem bark for albino rats

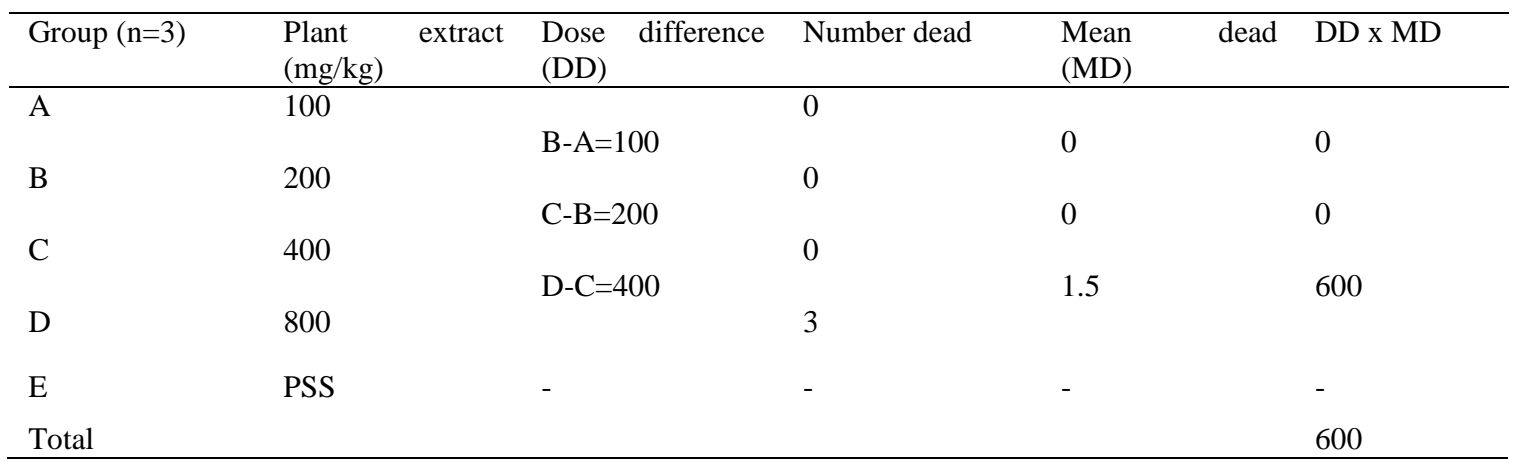

$\mathrm{LD}_{50}=\mathrm{LD}_{100}-(\mathrm{DD} \times \mathrm{MD} / \mathrm{n})=800-(600 / 3)=600$

$\mathrm{LD}_{50}=600 \mathrm{mg} / \mathrm{kg}$ body weight.

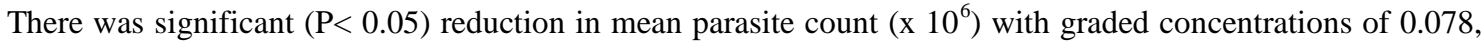
$0.313,0.625,1.25$ and $2.50 \mathrm{mg} / \mathrm{ml}$ having $3.5 \pm 0.02,3.4 \pm 0.05,3.3 \pm 0.04,3.2 \pm 0.03$ and $3.1 \pm 0.0$ respectively compared with the normal control (PSS) with $4.0 \pm 0.1$ count (Table 3 ).

Table 4 shows the in vitro efficacy of the crude aqueous extract of Guiera senegalensis stem bark against $T$. brucei activity. There was a $100 \%$ inhibition of motility of $T$. brucei at descending extract concentrations of $40 \mathrm{mg} / \mathrm{ml}$ and $20 \mathrm{mg} / \mathrm{ml}$. 


\section{A. A. Biu and others}

Table 3. In vitro efficacy of the crude aqueous extract Guiera senegalensis stem bark on T. brucei

\begin{tabular}{ccccc}
\hline Extract & \multicolumn{4}{c}{ Parasite count* minutes post inoculation (MPS) $\left(\mathrm{x} 10^{6}\right)$} \\
\cline { 2 - 5 }$(\mathrm{mg} / \mathrm{ml})$ & $30 \mathrm{mins}$ & $60 \mathrm{mins}$ & $90 \mathrm{mins}$ & $120 \mathrm{mins}^{\mathrm{b}}$ \\
\hline PSS (contro) & $4.0 \pm 0.01^{\mathrm{a}}$ & $4.2 \pm 1.8^{\mathrm{a}}$ & $4.5 \pm 005^{\mathrm{a}}$ & $4.5 \pm 0.05^{\mathrm{a}}$ \\
& $(4.0-4.2)$ & $(4.2-4.5)$ & $(4.4-4.6)$ & $(4.4-4.6)$ \\
0.078 & $3.5 \pm 0.02^{\mathrm{b}}$ & $4.0 \pm 0.01^{\mathrm{a}}$ & $4.2 \pm 0.09^{\mathrm{b}}$ & $4.3 \pm 0.05^{\mathrm{b}}$ \\
& $(3.5-3.7)$ & $(3.9-4.0)$ & $(4.2-4.3)$ & $(4.3-4.44)$ \\
0.156 & $3.6 \pm 0.05^{\mathrm{a}}$ & $4.1 \pm 0.05^{\mathrm{b}}$ & $4.0 \pm 0.06^{\mathrm{b}}$ & $4.0 \pm 0.05^{\mathrm{b}}$ \\
& $(3.5-3.6)$ & $(3.9-4.0)$ & $(4.0-4.1)$ & $(4.0-4.1)$ \\
0.313 & $3.4 \pm 0.05^{\mathrm{b}}$ & $3.6 \pm 0.04^{\mathrm{b}}$ & $3.8 \pm 0.05^{\mathrm{b}}$ & $3.8 \pm 0.04^{\mathrm{b}}$ \\
& $(3.4-3.5)$ & $(3.6-3.8)$ & $(3.8-3.9)$ & $(3.8-3.9)$ \\
0.625 & $3.3 \pm 0.04^{\mathrm{b}}$ & $3.6 \pm 0.05^{\mathrm{b}}$ & $3.6 \pm 0.0^{\mathrm{b}}$ & $3.6 \pm 0.04^{\mathrm{b}}$ \\
& $(3.3-3.4)$ & $(3.6-3.7)$ & $(3.6-3.7)$ & $(3.6-3.8)$ \\
1.25 & $3.2 \pm 0.03^{\mathrm{b}}$ & $3.6 \pm 0.04^{\mathrm{b}}$ & $3.5 \pm 0.04^{\mathrm{b}}$ & $3.4 \pm 0.04^{\mathrm{b}}$ \\
& $(3.2-3.3)$ & $(3.6-3.8)$ & $(3.5-3.7)$ & $(3.4-3.6)$ \\
2.50 & $3.1 \pm 0.04^{\mathrm{b}}$ & $3.5 \pm 0.03^{\mathrm{b}}$ & $3.2 \pm 0.02^{\mathrm{b}}$ & $3.2 \pm 0.02^{\mathrm{b}}$ \\
& $(3.1-3.3)$ & $(3.5-3.7)$ & $(3.2-3.4)$ & $(3.2-3.4)$ \\
5.00 & $3.0 \pm 0.02^{\mathrm{b}}$ & $3.2 \pm 0.04^{\mathrm{b}}$ & $3.1 \pm 0.01^{\mathrm{b}}$ & $3.2 \pm 0.01^{\mathrm{b}}$ \\
& $(3.0-3.2)$ & $(3.2-3.3)$ & $(3.1-3.3)$ & $(3.2-3.3)$ \\
10.0 & $2.8 \pm 0.01^{\mathrm{b}}$ & $3.0 \pm 0.02^{\mathrm{b}}$ & $3.1 \pm 0.01^{\mathrm{b}}$ & $3.0 \pm 0.01^{\mathrm{b}}$ \\
& $(2.8-3.2)$ & $(3.0-3.2)$ & $(3.1-3.3)$ & $(2.8-3.0)$ \\
20.0 & $0.0 \pm 0.0$ & $0.0 \pm 0.0$ & $0.0 \pm 0.0$ & $0.0 \pm 0.0$ \\
40.0 & $0.0 \pm 0.0$ & $0.0 \pm 0.0$ & $0.0 \pm 0.0$ & $0.0 \pm 0.0$ \\
\hline
\end{tabular}

*Mean \pm SD (range) of 4 replicates; Columns mean values bearing different superscripts are statistically significant $(\mathrm{P}<$ $0.05)$

Table 4. Mean \pm SD (range) inhibition of motility of $T$. brucei upon exposure to G. senegalensis leaf crude aqueous extract

\begin{tabular}{ccccc}
\hline Extract & \multicolumn{4}{c}{ Mean \pm SD $(\%$ inhibition $)$ MPI } \\
\cline { 2 - 4 }$(\mathrm{mg} / \mathrm{ml})$ & 30 mins & $60 \mathrm{mins}$ & $90 \mathrm{mins}$ & $120 \mathrm{mins}$ \\
\hline PGB (Control) & $00 \pm 00$ & $00 \pm 00$ & $00 \pm 00$ & $00 \pm 00$ \\
0.078 & $6.8 \pm 3.95$ & $6.8 \pm 3.97$ & $5.9 \pm 3.00$ & $3.5 \pm 0.91$ \\
& $(2.4-10.0)$ & $(2.410 .0)$ & $(3.2-8.0)$ & $(3.4-6.0)$ \\
0.156 & $10.5 \pm 4.0$ & $8.7 \pm 3.0$ & $10.5 \pm 2.4$ & $9.7 \pm 0.7$ \\
& $(5.2-12.0)$ & $(5.1-10.0)$ & $(9.5-12.5)$ & $(9.2-10.0)$ \\
0.313 & $10.2 \pm \pm 3.01$ & $10.2 \pm 3.0$ & $10.5 \pm 2.40$ & $11.5 \pm 5.6$ \\
& $(6.1-13.9)$ & $(6.1-13.9)$ & $(8.0-13.0)$ & $(9.0-15.0)$ \\
0.625 & $10.5 \pm 3.9$ & $10.2 \pm 3.0$ & $10.5 \pm 3.9$ & $15.3 \pm 4.0$ \\
& $(5.0-13.6)$ & $(6.1-13.9)$ & $(5.0-13.6)$ & $(6.0-15.0)$ \\
1.25 & $14.5 \pm 4.4$ & $12.2 \pm 5.0$ & $15.5 \pm 4.0$ & $16.9 \pm 2.29$ \\
& $(11.5-17.5)$ & $(10.2-15.0)$ & $(6.0-15.0)$ & $(13.8-19.3)$ \\
& $18.5 \pm 3.0$ & $12.3 \pm 3.94$ & $15.52 \pm 1.93$ & $18.5 \pm 3.0$ \\
5.50 & $(15.5-25.3)$ & $(7.5-15.0)$ & $(13.8-17.2)$ & $(15.1-21.5)$ \\
& $20.5 \pm 5.0$ & $23.5 \pm 5.4$ & $30.5 \pm 7.7$ & $30.5 \pm 7.7$ \\
10.0 & $(18.8-23.5)$ & $(20.5-29.9)$ & $(25.7-30.0)$ & $(25.7-30.0)$ \\
& $25.7 \pm 8.5$ & $23.6 \pm 2.7$ & $28.4 \pm 24.3$ & $30.5 \pm 3.0$ \\
40.0 & $(20.5-29.5)$ & $(20.8-27.2)$ & $(25.3-30.7)$ & $(29.5-32.0)$ \\
& 100.0 & 100.0 & 100.0 & 100.0 \\
\end{tabular}

PBG= phosphate buffer glucose solution, MPI= Minutes Post Inoculation

NOTE: Values are Meant \pm Standard deviation (SD) and range of 4 replicates. 
The phytochemical screening of the crude aqueous extract of Guiera senegalensis stem bark indicated presence of tannins, terpenoids, alkaloids, flavonoids, saponins, anthraquinones and cardiac glycosides. Phlabotannins and cardenolides were not detected as described by Fiot et al. (2004).

The median lethal dose $\left(\mathrm{LD}_{50}\right)$ of the aqueous extract of $\mathrm{G}$. senegalensis stem bark was $600 \mathrm{mg} / \mathrm{kg}$ indicative of moderate toxicity (Hodge and Sterner, 1949; Bruno et al., 2013). The antitrypanosomal activities of the aqueous extract of Guiera senegalensis stem bark in vitro in this study could be attributed to the composition of phytochemicals. Some plant extracts have been demonstrated to contain potent trypanocidal constituents (Igweh and Onabanjo, 1989; Atawodi, 2005), and that plant trypanocidal activity should be taken within the context of the plant part and the solvent extract tested (Atawodi, 2005). It is difficult to speculate the mechanism by which these extracts exhibit their antitrypanosomal activity since the active ingredients were not isolated. However, accumulated evidence suggested that many natural products exhibit their antitrypanosomal activity by virtue of their interference with the redox balance of the parasite acting either on their respiratory chain or cellular defense against oxidative stress. This is because natural products possess structures capable of generating radicals that may cause peroxidative damage to trypanothione reductase that is very sensitive to alteration in redox balance. It is also known that some agents act by binding with the kinetoplast DNA of the parasite (WHO, 2011).

In conclusion, the crude aqueous extract of Guiera senegalensis stem bark contains many natural products that may exhibit their antitrypanosomal activity. This result only suggests that crude aqueous extract of $G$. senegalensis stem bark has potential to provide therapeutic agents for treatment of African trypanosomiasis. Further in vivo studies on the crude aqueous extract of $G$. senegalensis stem bark is therefore recommended.

\section{REFERENCES}

1. Aliu YO and Nwude E (1982). Veterinary Pharmacology and Toxicology Experiments. Baraka Press and Publishers, Nigeria. pp. 104-109.

2. Aniagu SO, Binda LG, Nwinyi FC, Orisadipe A, Wambebe C and Gamanie K (2005). Antidiarrhoeal and ulcerprotective effects of the aqueous root extract of Guiera senegalensis in rodents. Journal of Ethnopharmacology 97 : 549-554.

3. Atawodi SE (2005). Comparative In vitro trypanocidal activities of petroleum ether, chloroform, methanol and aqueous extracts of some Nigerian savannah plants. African Journal of Biotechnology 4: 177-182.

4. Bruno, D Demoro B, Rossi M, Caruso F, Liebowitz D, Olea-Azar C, Kemmerling U, Maya JD, Guiset H, Moreno V, Pizzo C, Mahler G, Otero L and Gambino D (2013). Potential mechanism of the antitrypanosomal activity of organoruthenium complexes with bioactive thiosemicarbazones. Biological Trace Elements Research 153: 371381.

5. Fiot J, Ollivier E, Timon-David P and Balanzard G (2004). Guiera senegalensis J.F Gmel. (Combretaceae). Recent Research Development in Plant Science 2: 267-277.

6. Gutteridge WE (1985). Existing chemotherapy and its limitations. British Medical Bulletin 41: 162-168.

7. Herbert WJ and Lumsden WH (1976). Trypanosoma brucei method of estimating the host's parasitemia. Experimental Parasitology 40: 427-431.

8. Hodge HC and Sterner JH (1949). Toxicity Rating. American Industrial Hygiene Association Quarterly 10: 93-96. DOI: $10.1080 / 00968204909344159$.

9. Igweh AG and Onabanjo AO (1989). Chemotherapeutic effects of Annona senegalensis in Trypanosoma brucei infection in mice. Journal of Ethnopharmacology 30: 307-313.

10. Kerharo J, Bouquet A and Heintz R (1948). Le Wilinwiga des Mossi (Guiera senegalensis Lam), ses usages therapeutiques indigenes et sonappiication treatment des diarrhea choleriformes. Acta Tropica 5: 344-348.

11. Nok AJ (1993). Azaanthraquinone inhibits respiration and Invitro growth of long slender bloodstream forms of Trypanosoma congolense. Cell Biochernistry and Fucntion 20: 205-212.

12. Trease GE and Evans WC (2002). Pharmacognosy $15^{\text {th }}$ Edition Saunders. pp. 214-393.

13. Vanhollebeke B, True P, Poelvoorde P, Pays A, Joshi PP, Katti R, Jannin JG and Pays E (2006). Human Trypanosoma evansi infection linked to a lack of apolipoprotein 1. New England Journal of Medicine 355: 27522756.

14. World Health Organization. (2011). African Trypanosomiasis. Retrieved April, 1, 2011, from the WHO.

15. WHO media centre (2012). Fact sheet NO. 259: African trypanosomiasis or sleeping sickness. 